\title{
Guidelines - Inflation or Help in Clinical Routine?
}

\author{
Manfred Kaufmann \\ Department of Obstetrics and Gynecology, J. W. Goethe University, Frankfurt/M., Germany
}

David Sackett, one of the pioneers of the so-called evidencebased medicine raised the question: 'What is good medicine?' and answered that good medicine is medicine which is needed by the patient and is handled and known by the doctor. Some conflicting key words are associated with this topic. Theory and experience, formalism and intuition, reglementation and freedom of therapy are the antipodes which have to be balanced in every-day clinical routine. However, only $20-40 \%$ of clinical decisions are based on rational motivations [1]. Especially the 'cult of the individual decision-making' of the physician is very strong in Germany. The medical knowledge about breast cancer, including clinical and basic science issues, has a half-life of about two years, and new scientific findings take 8-10 years before they are implemented in medical care. Guidelines for the most frequent diseases should give support for treatment decisions, help to offer the patient a state-of-theart therapy and protect the individual patient as well as the treating physician from suboptimal outcome. Hebert-Croteau et al. [2] could demonstrate that treatment of breast cancer patients is associated with significant survival benefit and additionally Minter et al. [3] found a reduction of treatment costs with comparable quality of life using a standard therapy in contrast to individualized treatment. These data emphasize the need and benefit of guidelines. But efficacy of a guideline depends on its quality, acceptance, publicity and practicability, as well as the financial resources and patients' acceptance.

Currently several important, high-quality guidelines exist (e.g. ASCO www.asco.org, NCCN www.nccn.org, AGO www.agoonline.de, S3 guideline breast cancer www.awmf-leitlinien.de) and all of them have different definitions for 'quality' and 'guideline'. Some guidelines give conflicting recommendations and lack methodological quality. Moreover, there are several issues of local and nationwide structural differences between different countries which explain some of the differences and should be taken into account when establishing guidelines.
One of the striking advantages of guidelines is to incorporate a higher transparency into the information overload and thus to reduce the proportion of 'opinion-based' or even 'company-based' treatment decisions. In this context the definition of liability when an individual treatment decision does diverge from current guidelines is a critical issue. Implementation of guidelines at an institution is necessarily associated with quality management and monitoring of such procedures by independent organizations.

The interpretation of scientific findings is largely biased by the influence of several factors. The results of many trials are flawed by errors in trials design (e.g. comparison of different dosages, patient cohorts, or definition of surrogate end points). Moreover, the analysis of raw data by the financier of a trial and not by the principal investigator carries the risk of misdirected or manipulated interpretation. Therefore the issue of positive appraisal of negative trial results should be discussed and publication of such studies in high-impact journals should be considered more often. A so-called negative trial belongs indispensably to evidence-based medical knowledge. For the future new endpoints must be defined not only encompassing clinical (disease-free survival instead of overall survival) but also socio-economic endpoints since the increasing costs of modern anticancer therapies must be borne by the community. All of these aspects should be considered in treatment guidelines. Thus, transfer of the contents of guidelines is crucial, and continuous certified education has to be performed by certified educators.

In summary it might be concluded that an inflation of guidelines can be observed but is not necessarily associated with impaired health care. The establishment of nationwide guidelines comprises the implementation of high-quality international recommendations into a national or local context, the monitoring by independent quality assurances and the transfer of guideline contents by uniform and certified educations. For

\begin{tabular}{ll}
\hline KARGER & @ 2008 S. Karger GmbH, Freiburg \\
Fax +49 76145207 14 & Accessible online at: \\
$\begin{array}{l}\text { E-mail Information@Karger.de } \\
\text { www.karger.com }\end{array}$ & www.karger.com/brc \\
&
\end{tabular}

Prof. Dr. med. Dr. h.c. Manfred Kaufmann

Universitätsfrauenklinik

Johann-Wolfgang-Goethe-Universität

Theodor-Stern-Kai 7, 60596 Frankfurt/M., Germany

Tel. +49 69 6301-5115, Fax -6317

E-mail m.kaufmann@em.uni-frankfurt.de 
this reason the interdisciplinary development of guidelines in a country is helpful to reduce 'guideline inflation', makes treatment decisions more transparent and is associated with treatment optimization and survival benefit as well as cost reduction.

Guidelines are not cooking recipes but they can give assistance and emerge by the fusion of evidence-based medicine and expert opinion. Also prognostic and predictive tools like 'adjuvant online' may only support the physician's decision. Guidelines have to be up-to-date and should be renewed every two years. However, I hope that only one guideline will be accepted in Germany in the future.

\section{References}

Antman EM, Lau J, Kupelnick B, Mosteller F, Chalmers TC: A comparison of results of meta-analyses of randomized control trials and recommendations of clinical experts. Treatments for myocardial infarction. JAMA 1992;268:240-248.

2 Hébert-Croteau N, Brisson J, Latreille J, Rivard M, Abdelaziz N, Martin G: Compliance with consensus recommendations for systemic therapy is associated with improved survival of women with node-negative breast cancer. J Clin Oncol 2004:22:3685-3693.

3 Minter RM, Spengler KK, Topping DP, Flug R, Copeland EM 3rd, Lind DS: Institutional validation of breast cancer treatment guidelines. J Surg Res 2001;100: 106-109. 